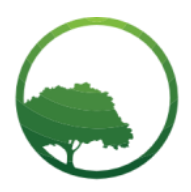

Research in Business \& Social Science

\title{
Investigating the moderating role of intercultural factors on consumer cross-shopping behavior: Bridging the prejudice
}

\author{
Hayiel Hino \\ Department of Economics \& Business Administration Ariel 40700, Israel
}

\author{
A R T I CLE IN F O \\ Article history: \\ Received 19 Feb 20 \\ Received in revised form 05 March 20 \\ Accepted 13 March 20 \\ Keywords: \\ Cross-shopping, Prejudice, Intergroup \\ contact, Social interaction \\ Acculturation \\ JEL Classification: \\ M30, L10
}

\begin{abstract}
A B S T R A C T
The concept of prejudice has become increasingly important to scientific thinking about relations between groups. Yet, despite extensive research, little is known about how prejudice affects consumer buying behavior, especially regarding activities that involve purchasing products and services thereby crossing to suppliers from the dominant community. The purpose of this study is twofold: to examine the influence of both positive and negative prejudices on cross-shopping intention in the context of an ethnic minority-majority group relationship; and, to investigate the moderating influence of intercultural-related factors (i.e. online contact, social interaction, and acculturation) on the relationship between negative prejudice and cross-shopping intention. A sample consisting of 202 respondents was obtained from across ethnic-minority consumers (the Israeli Arabs) who routinely interact online and offline with individuals from the majority population (Israeli Jews). The conceptual framework and hypothesis are tested using the partial least squares analyzes (PLS). The study results provide a better understanding of the conflicting effects of positive and negative prejudice on crossshopping intention. Additionally, results shed light on the moderating role of intercultural factors on the relationship between negative prejudice and cross-shopping intention. Implications are identified together with consideration of the study limitations and avenues for future research.
\end{abstract}

(C) 2020 by the authors. Licensee BSC International Publishing, Istanbul, Turkey. This article is an open access article distributed under the terms and conditions of the Creative Commons Attribution (CC BY) license (http://creativecommons.org/licenses/by/4.0/).

\section{Introduction}

Prejudice refers to ideas, beliefs, feelings, and attitudes that people have about other less familiar groups as a whole or individuals within those groups, based on their perceived group membership (e.g., race, class, gender, religion, and sexual orientation). Prejudice does not necessarily occur only in one direction (Brylka, Jasinskaja-Lahti, \& Mähönen, 2016). Interacting social groups can be mutually prejudiced, in particular when members of each social group possess limited knowledge about members from the other group.

Prejudice also can be either positive or negative. Negative prejudices are unfavorable opinions or feelings, stereotyped beliefs, and negative evaluative reactions such as disapproval, dislike, and a tendency to discriminate against outgroup members (Dovidio et al., 2002). In contrast, positive prejudices typically occur when individuals develop preferences that lead to distorting any new information so that it will reinforce those preferences, and discounting data that does not.

A review of many previous studies points to a vast majority skewed towards studying the influence of negative prejudice, while research on positive prejudice is sparse. Moreover, to the best of our knowledge, no research has yet investigated the simultaneous conflicting effects of positive and negative prejudice types on consumer behavior.

Notwithstanding this conceptual complexity, reducing prejudice has frequently been discussed in past studies. This body of research on prejudice reduction encompasses work on interventions such as re-education, mutual identification, empathy arousal, and intergroup social contact (Brylka, Jasinskaja-Lahti, \& Mähönen, 2016; Paluck \& Green, 2009). For example, research investigating the influence of social interactions on perceived prejudice points to positive effects on intergroup perceptions and attitudes regarding the reduction of negative stereotypes and emotions between different ethnic and cultural background groups (Pettigrew et al., 2011).

* Corresponding author. ORCID ID: 0000-0002-6046-8890 
A meta-analysis of 515 studies conducted in a variety of intergroup contexts showed a relatively strong negative relationship between intergroup contact and perceived prejudice (Pettigrew \& Tropp, 2006). Yet, despite this extensive research, little is known about how reduced prejudice affects consumer behavior especially regarding activities that involve purchasing products and services from outgroup marketers. Moreover, the prejudice literature lacks an integrative approach to measuring the prejudice - consumer behavior link, with many studies substituting acculturation for it. Consequently, it seems that research did not progress, as most empirical contributions to this field of research have focused on attitudinal and emotional aspects of prejudice and, to a lesser extent, on assessing the influence of reduced prejudice on behavioral intention.

Thus, the aim of this study is twofold. Firstly, to examine the influence of both positive and negative prejudices on cross-shopping intention in the context of an ethnic minority-majority group relationship (the Israeli Arab and Jewish populations). Secondly, to investigate the moderating influence of intercultural factors on the relationship between negative prejudice and cross-shopping intention. For this purpose, we propose a conceptual framework that builds on the intergroup contact theory (Allport, 1954), and various previous studies investigating the influence of intercultural-related factors in the context minority-majority group relationship. Contact theory suggests that negative emotions and feelings associated with prejudices toward outgroup members diminish as interactions between minority and majority groups expand. This, in turn, translates to enhanced reciprocal intergroup relations. Moreover, we argue that intercultural factors moderate the negative effect of prejudice on consumer switching intention thus bridging behavioral gaps between individuals from highly distant cultures.

The study begins with a background discussion regarding the influence of intergroup online contact, perceived positive prejudice and intercultural factors. The study then integrates relevant themes from this research field into a theoretical framework, with the purpose of developing and empirically testing a conceptual framework that examines the influence of intergroup contacts on the relationship between perceived prejudice and cross-shopping intention (see Figure 1). The third part of the study discusses the methods used for a consumer behavior study designed to test these hypotheses. Sampling for the study was conducted within the Israeli-Arab cultural community. This minority was sampled because they (a) comprise a considerable percentage of Israeli society; (b) preserve a distinct cultural orientation and unique way of life yet represent a high degree of heterogeneity in many features including cultural characteristics and social status; and (c) routinely interact with the dominant culture (Hino, 2014). A structural model was built including all the antecedents and relevant relationships. Structural Equation Modelling (SEM) employing WarpPLS 7.0 was used for the analysis, enabling us to examine the hypothesized causal paths among the constructs by performing a simultaneous test. Section four presents the study findings whereas the final section concludes the study and provides implications of the analysis.

\section{Literature Review}

\section{The conflicting influence of prejudice on cross-shopping}

Prejudices made in a country by the dominant culture can significantly influence the prejudiced groups' attitudes and behaviors. Consequently, perceived prejudice has been acknowledged as a key factor affecting individuals' emotions, feelings, and attitudes toward outgroup members. Moreover, the outcome of numerous studies addressing the prejudice-behavior link in a variety of situations points to prejudice that can strongly influence individuals' beliefs, attitudes, and actual behavior (Byrd, 2014; Crisp \& Turner, 2009; Dovidio et al., 2002; Fujimoto \& Hartel, 2004; Knowles, Lowery, \& Shaumberg, 2010). For example, a study by Greenwald, Smith, Sriram, Bar-Anan, and Nosek (2009) found prejudice predicts voting behavior, including for the 2008 elections, the first time in which an African American (Barack Obama) was elected president of the United States.

However, despite the concept that perceived prejudice often indicates either positive or negative influence, this concept has been largely restricted to indicating negative impacts. The information available on positive prejudices is minimal. This is especially pervasive in studies focused on ethnic-cultural, religious, racial, or national group membership-based prejudice (Dovidio, Eller, \& Hewstone, 2011; Ng, Kulik, \& Bordia, 2016). It is also evident in studies addressing the ethnic minority-majority group relationship. Findings from many of these studies have documented the negative attitudinal and actual responses of individuals from one ethnic group toward other outgroup members just because of their differences (Dovidio et al., 2002; Fujimoto \& Hartel, 2004). Moreover, according to these studies, relations between ethnic-cultural groups often involve distrust, suspicion, tension, and even conflict (Dovidio et al., 2002). Consequently, prejudice can strongly influence not only how individuals feel, but also how they behave and interact with those dissimilar to them (Fujimoto \& Hartel, 2004).

The current study investigates the conflicting influence of perceived negative and positive prejudices on cross-shopping intention in the context of an ethnic minority-group (Israeli Arabs). In this regard, studies conducted in Israel have documented negative intergroup attitudes between Jews and Arabs (Bar-Tal \& Teichman, 2005; Tessler, 2009). The negative intergroup tension between the two communities, which has intensified over the past two decades, means far more mutual negative prejudice between Jews and Arabs. However, as noted earlier, prejudice toward outgroup members can be simultaneously negative and positive (Dienstbier, 1970). That is, members of one group may be negatively prejudiced toward outgroup members in some areas, while they have positive feelings and attitudes in others. For example, as Hodge and colleagues (2008) point out, black male athletes are often perceived as less intelligent, yet more athletic than their white male counterparts. These stereotypes persist despite a number of high-profile examples to the contrary. Smith and Li (2010) cite another example of how conflicting feelings and attitudes influence behavior. In their study on Chinese consumers' willingness to boycott Japanese products they demonstrated the conflicting effects of perceived 
animosity, open hostility, and negative attitudes of Chinese consumers toward Japanese-made products, even though they view Japanese products as of superior quality, being produced in a highly developed country. Finally, in the context of the present study, Israeli Jews (the dominant population) are perceived by Arabs as dynamic; changers of both landscape and social order, and as portraying vigor, strength, and success. However, Arab attitudes toward Jews and the Jewish state have become more critical and militant during recent years. According to the study by Hermann, Cohen, Omar, Heller, and Lazar-Shoef (2017) a majority of Israeli Arabs believes that for the most part, the Israeli government has behaved inequitably and unfairly toward Arab citizens. Additionally, a high percentage of Arabs (43\%) reported that their feelings toward the State of Israel have become increasingly negative in recent years. Jews perceived Israeli Arabs as an enemy-affiliated security threat. The negative perceptions and emotions manifested by Jews towards Arabs are mutual.

Drawing on this previous work, it can be argued that the link of prejudice to consumer behavior can be viewed as a step closer towards linking the conflicting influences of prejudice to cross-shopping in the context of ethnic minority-majority group relationship. Cross-shopping is defined as "the process by which consumers conduct their shopping activities at two or more food stores thereby dividing their shopping basket between different stores" (Hino, 2017, p.3). This pattern allows consumers to preserve their relationship with current retailers as they continue directing a proportion of their shopping activities to those marketers, while crossing between current and new retailers (Hino, 2014). In line with this past research, here we define cross-shopping intention as the minority members' tendency to consider crossing to majority-group marketers for purchasing products and services, despite having refrained from doing so until now because of perceived negative prejudice. Accordingly:

H1a: The higher the perceived negative prejudice, the lesser the tendency to cross-shopping.

H1b: The higher the perceived positive prejudice, the greater the tendency to cross-shopping.

H1c: There will be a negative correlation between positive and negative prejudice.

\section{Cross-cultural Contact}

\section{Online Contact}

Online social networking has become an emerging cultural phenomenon. However, research on recent global social shifts in online social communications among consumers of diverse cultures and ethnicities highlighted the need for further research on the role online cross-cultural interactions play in individuals' consumption behavior (Demangeot, Broderick, \& Craig, 2015; Hanna, Rohm, \& Crittenden, 2011).

Cross-cultural contacts with, and exposure to, outgroup members have been conceptualized in many empirical studies as enablers of negative reduced-friction contact (Dovidio, Eller, \& Hewstone, 2011; Gaunt, 2011; Seger et al., 2014; Wojcieszak \& Azrout, 2016). This research stream is built on the contact theory, one of the leading theories regarding the reduction of intergroup prejudices (Allport, 1954). Intergroup contact theory states that individuals are very likely to develop a favourable perception of outgroup members if the interactions between the members are frequent and positive. This favourable perception will, in turn, lead to deeper understanding of, and a more positive attitude toward, outgroup members thereby increasing tolerance and reducing conflicts and prejudices (Brown \& Hewstone, 2005; Gaunt, 2011; Husnu, Mertan, \& Cicek, 2018). Findings from numerous prior studies have consistently shown that frequent exposure to outgroup members will improve intergroup relations and individual responses (Schumann, van der Linden, \& Klein, 2012; Segeret al., 2014; White \& Abu-Rayya, 2012). For example, Oyedele and Hernandez (2015) tested the influence of socio-political constructs and intergroup-based emotional variables on consumer decisions to purchase cross-ethnic products. It was found that intergroup contact and social-dominance orientation are important predictors of intergroup tolerance. Pettigrew and Tropp (2006), and Miller, Smith, and Mackie (2004) found intergroup contacts typically reduce negative prejudices and enhance positive emotions toward outgroup members. Likewise, Pettigrew and colleagues (2011) noted that higher contact frequency can yield greater probability of negative prejudice reduction. Similarly, Ng, Kulik, and Bordia (2016) demonstrated that individuals who experience more intergroup interactions may form more positive attitudes toward dissimilar individuals, perceiving these previous out-group members as belonging to their own social category.

Contact theory has also been applied to the online social contact environment in the context of intergroup minority-majority relationships. Most research that discusses the effects of online contact includes studies focusing on the positive outcome of online interactions, suggesting that negative attitudes held by one group toward another emanate from a lack of knowledge about that group (White \& Abu-Rayya, 2012). We build on this rich research stream, claiming that online interpersonal contacts with outgroup members facilitate mutual learning about the distinct groups thus leading to more positive attitudes toward outgroup members, which in turn can reduce negative prejudices and improve intergroup relations (Dovidio, Eller, \& Hewstone, 2011; Hino, 2015; Mor, Ron, \& Maoz, 2016; Wojcieszak \& Azrout, 2016). Thus:

H2a: Online contacts between minority and majority group members will reduce perceived negative prejudice.

In assessing the moderating influence of online contact on the relationship between negative prejudice and consumer cross-shopping decisions we rely on numerous previous studies investigating the link between personal contact through social networks and consumer behavior. 
Consumers are increasingly seeking information through social network platforms to guide their future purchasing decisions. This has led to the development of e-WOM chats which gave consumers the opportunity to exchange recommendations on products and services they have experienced (Erkan \& Evans, 2016). Findings from various empirical research investigating the influence of eWOM on consumer behavior have pointed out that effective use of social networks websites can have direct effects on purchasing decisions (Gautam \& Sharma, 2017; Hinz et al., 2011; Mortazavi, Esfidani, \& Barzoki, 2014). In the context of intergroup minoritymajority relationship, social networking has been reported to facilitate cross-ethnic communications by offering simple platforms to interact with outgroup members (Martinez et al., 2014). This has motivated many marketers to use social network websites to engage minority consumers thereby motivating them to participate in eWOM-related activities, including receiving and sharing comments, reviews, and recommendations with outgroup members (Zaglia, 2013). Applying these ideas to our context, we posit that consumers who feel less perceived prejudice due to online contact will demonstrate higher motivation to adapt their buying behavior (i.e. willingness to cross-shopping) upward, which will then change (upward) their shopping behavior. Thus online contact will increase consumer willingness to cross to outgroup suppliers through moderating the negative relationship between perceived prejudice and cross-shopping intention. Accordingly, we hypothesize:

H2b: Online contact will moderate the relationship between negative prejudice and cross shopping intention.

\section{Social interaction}

Social interactions involving minority-majority group members provide the former with opportunities to learn a new behavioral repertoire first-hand that is deemed appropriate and useful in the majority group context (Berry, 1997). Interactions between minority and majority group members are positively related to the minority's sense of belonging to the dominant culture (Glass \& Westmont, 2014). This in turn, can change ethnic-group members' perceptions and responses in ways that minimize prejudice toward dominant group members. Furthermore, by possessing more willingness towards adapting to the dominant culture, minority members can increase their interaction with majority group members by learning culture-specific knowledge (Shafaei \& Abd Razak, 2018). Indeed, Minority consumers participating in social interactions (e.g. hosting outgroup members at their houses, and maintaining close social relationships with them) face unique challenges, including disapproving social norms and conservatism (Eleta \& Golbeck, 2014; Fox $\&$ Warber, 2015). Concurrently, however, social interactions facilitate cross-ethnic communications (Martinez., 2014) from which ethnic-group members may significantly benefit (Oh, 2016).

Aside from the evidence in the literature, we expect social interactions to positively affect minority members' buying decisions. The logic is that individuals with a sense of belonging to, or at least solidarity with, the dominant group as a result of frequent interactions, will also have greater tendency to adopt behavioral patterns, including shopping and consumption behavior associated with the dominant group. This implies that minority-group members will demonstrate more willingness to cross to the outgroup retail system for purchasing products and services. Based on both logic and evidence from the literature, we hypothesize that:

H3a: There will be a negative relationship between social interactions and perceived negative prejudice.

H3b: Social interactions will moderate the negative relationship between prejudice and cross-shopping intention.

\section{Acculturation}

Acculturation refers to the acquisition of new cultural patterns and practices in wide ranging areas, including the learning of new norms, and practices (Berry, 2005).

Acculturation has long been discussed in the context of ethnic minority-majority group relations (Cleveland \& Chang, 2009). As such, acculturation develops as minority members socialize and come into continuous contact with the dominant culture (the majority group), (Üstüner \& Holt, 2007). Consumer acculturation thus involves adapting to the dominant culture that may result in different lifestyle patterns (Taušová et al., 2019; Vijaygopal \& Dibb, 2012).

Yet, the issue of whether to remain well-distinguished or to adopt values and norms of the dominant culture is affected by minority members' perceived prejudice toward the dominant group. Studies investigated the acculturation-prejudice link in a variety of situations provide evidence for the proposed relationship between the two constructs (Greenland \& Brown, 2005). For example, Zick, Wagner, van Dick, and Petzel, (2001) reported in a study focused on the connections between prejudice and selected attitudes toward acculturation in Germany that minorities members who have an assimilative orientation demonstrated less prejudice against the dominant majority. That is, the more highly acculturated minority-group consumers are, the lower the prejudice perception toward the dominant population members. Therefore, we hypothesize:

H4a: There will be a negative relationship between acculturation and negative prejudice.

Acculturation also has been found to affect minority-group members' consumption behavior. This is evident in various studies investigating the acculturation-shopping behavior link (A' lvarez, Dickson, \& Hunter, 2014; Dato-on et al., 2006; De Mooij \& Hofstede, 2011; Leo, Bennett, \& Hartel, 2005; Segev, 2014). Underlying this research stream is the idea that adaptation to the dominant culture is manifested in changes in consumers' shopping decisions (Lee, Fairhurst, \& Dillard, 2002). For example, a study by Quester, Karunaratna, and Chong (2001) focusing on aspects of consumer behavior, including product evaluation and purchase behavior, found acculturation affects pre-purchase decision-making of Australian consumers. Similar findings are reported in other 
studies testing this link (Bojanic \& Xu, 2006; Chen, Aung, \& Kanetkar, 2005). More recently, a study by Segev (2014) investigating the acculturation effect on consumer decision-making among ethnic consumers found that highly acculturated consumers exhibit familiarity and confidence when dealing with the marketplace.

We rely on this research stream in investigating the influence of acculturation on consumer cross-shopping intention, in particular on studies found ethnic-minority consumers deal with marketplace complexity through applying inherent strategies that determine their shopping patterns (Lysonski \& Durvasula, 2013). As such, it is reasonable to assume that individuals who become more acculturated to the dominant culture, their shopping behaviors will change accordingly. In this case, they would be more likely to adopt new shopping patterns such as cross-shopping to outgroup suppliers.

H4b: Acculturation will moderate the negative relationship between prejudice and cross-shopping intention.

The acculturation literature suggests that acculturation involves aspects such as online communication, and social interaction with dominant-group members (Josiassen, 2011; Kim, Laroche, \& Tomiuk, 2001). A growing body of work demonstrates the importance of these dimensions in the acculturation process. For instance, a study by McKelvy and Chatterjee (2017) examined the role of internet media and of social interaction dimensions in the acculturation process of Muslim women in the United States pointed to a positive relationship between online interaction with members from the dominant culture and social networks choice and their desire to acculturate. Similar findings were reported in studies examined the relationship between acculturation of foreign students to the host country and their use of social media and online communication when they study abroad (Greenland \& Brown, 2005; Sandel, 2014). Hence, the hypotheses:

H5: There will be a positive relationship between online contact and acculturation.

H6: There will be a positive relationship between social interaction and acculturation.

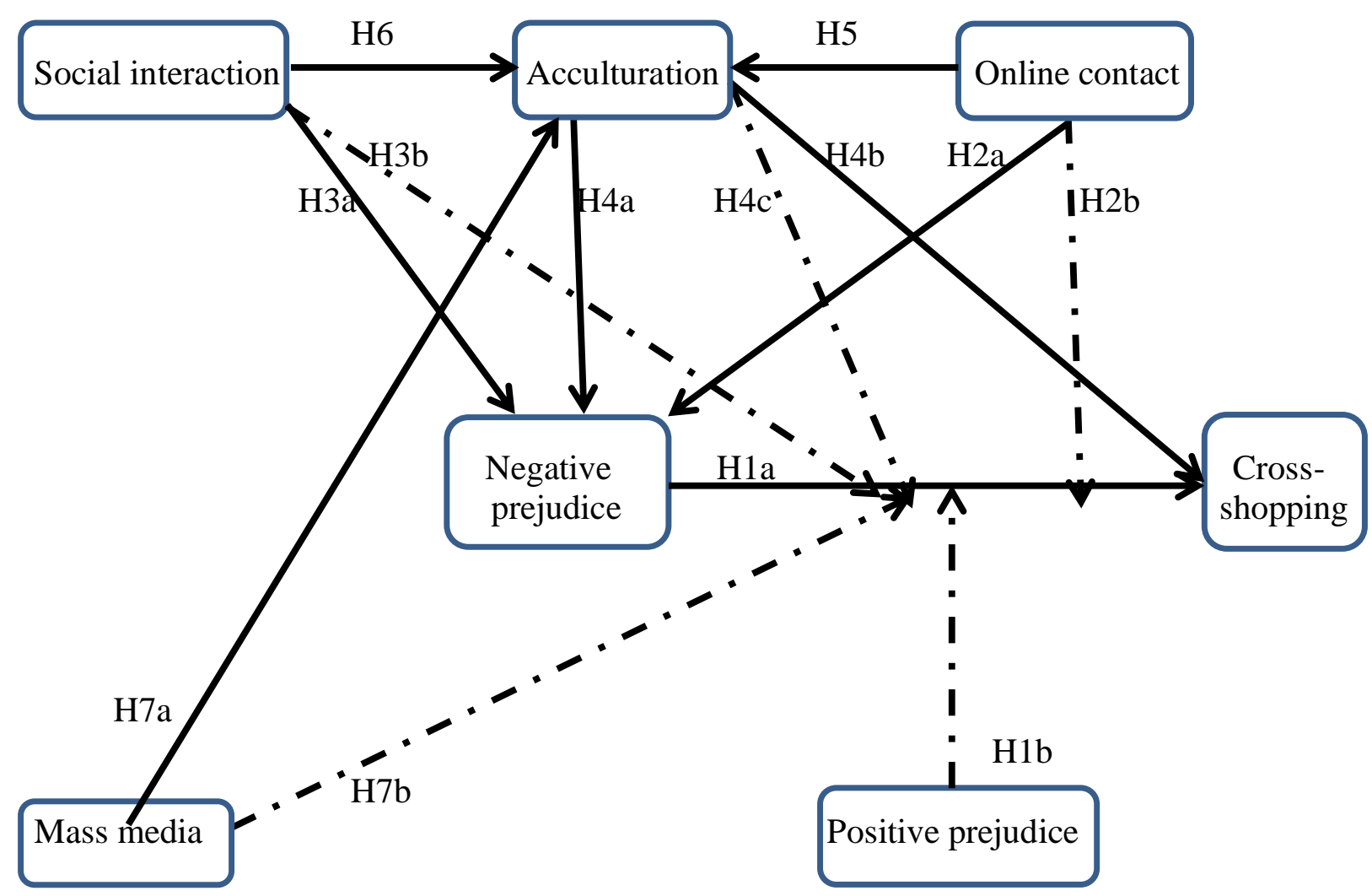

Fig. 1: Conceptual model 


\section{Research and Methodology}

\section{Application}

The Arab and Jewish populations in Israel are the setting for this study. Israel is a multi-ethnic society inhabited by Jews and Arabs. Israeli Arabs constitute an ethnic-cultural minority living in a largely Jewish country. They comprise $21 \%$ (1.8 million) of Israel's citizens and enjoy civil rights equal to those of the Jewish majority. However, despite this, the rights of Arab society in Israel as an ethnic minority have remained limited as this population is not recognized as a minority with collective rights. Moreover, Arabs in Israel are still excluded and discriminated against in many ways and lack full civil equality. They suffer from institutional discrimination manifested by the unequal distribution of resources and funds (Lavie, 2018). Most Arab citizens face non-institutional social discrimination manifested in everyday life. The disparities between the Arab and Jewish societies continue to grow, despite significant improvements in Arabs' socioeconomic status. These disparities are especially prominent regarding education, employment, wages, wealth, and poverty rates.

\section{Research Design}

\section{Questionnaire}

A two-part questionnaire was developed to solicit the necessary data for this study. The first part investigated the respondents' socioeconomic and demographic profile. The second dealt with the investigation of seven constructs and three moderating variables that comprise the conceptual framework of this study (see Figure 1). The constructs were presented to the subjects in question form, which they answered using a 5-point Likert scale. The data for this study was collected by telephone during September 2017. The telephone interviews were conducted by a professional research company specializing in collecting data from household samples. A sample of 202 respondents was obtained from across the Israeli Arab population. Following Mesch (2012), Vijaygopal and Dibb (2012), Wimmer and Soehl (2014), and Hino (2014; 2017) data were collected about perceived prejudice, intercultural-related factors associated with cross-shopping intention. In particular, respondents were asked about their positive and negative feelings and attitudes toward majority-group members (see Table 1). Respondents were questioned about their intention to cross to majority marketers for purchasing particular products and services. These questions were based on past studies that discussed the impact of online contacts on improving intergroup relations and individual responses (Dovidio, Eller, \& Hewstone, 2011; Hanna, Rohm, \& Crittenden, 2011; Gaunt, 2011; Wojcieszak \& Azrout, 2016).

\section{Reliability and Validity}

To ensure that the items used to operationalise the constructs of interest were internally consistent and free of measurement errors, reliability analysis was carried out using Cronbach's alpha. Internal consistency reliability coefficients for research constructs were higher than the recommended levels of 0.70 (range from 0.74 for cross-shopping intention, to 0.94 for negative prejudice; see Table 1 .

Table 1: Item loadings constructs' reliability and validity measures

\begin{tabular}{|c|c|c|c|c|}
\hline Construct & Item & Loadings & $\begin{array}{l}\text { Std. } \\
\text { Coef }\end{array}$ & $\begin{array}{l}\text { Cronbach } \\
\text { alpha }\end{array}$ \\
\hline Negative prejudice & 1. Israeli Jews are untrustworthy & .85 & .78 & .76 \\
\hline \multirow[t]{2}{*}{ (adapted: Olson, 2009) } & $\begin{array}{l}\text { 2. Arabs will never achieve a high level of progress because of } \\
\text { Israeli Jews }\end{array}$ & .9 & .76 & \\
\hline & 4. Israeli Jews are aggressive & .87 & .77 & \\
\hline $\begin{array}{l}\text { Social interaction } \\
\text { (adapted: }\end{array}$ & $\begin{array}{l}\text { 3. I have frequent communication with some members outside my } \\
\text { community }\end{array}$ & .84 & .88 & .75 \\
\hline \multirow[t]{4}{*}{$\begin{array}{l}\text { Chiu, Hsu, \& Wang, } \\
\text { 2006) }\end{array}$} & $\begin{array}{l}\text { 2. I spend a lot of time interacting with some members outside my } \\
\text { community. }\end{array}$ & .83 & .82 & \\
\hline & $\begin{array}{l}\text { 3. I maintain close social relationships with some members } \\
\text { outside my community. }\end{array}$ & .86 & .65 & \\
\hline & 4. It is important to participate in Israeli-Jews celebrations & .79 & .82 & \\
\hline & 5. I usually host some outgroup members in my house. & .61 & .55 & \\
\hline \multirow[t]{4}{*}{ Online contact } & $\begin{array}{l}\text { 1. participate in forums and discussion groups with members } \\
\text { from outside my community. }\end{array}$ & .85 & .93 & .84 \\
\hline & $\begin{array}{l}\text { 2. I spend a lot of time in online interaction with member outside } \\
\text { my community. }\end{array}$ & .8 & .89 & \\
\hline & $\begin{array}{l}\text { 3. I am pleased when I participate in online forums with outgroup } \\
\text { members. }\end{array}$ & .78 & .93 & \\
\hline & $\begin{array}{l}\text { 4. It is important to follow members from outside my community } \\
\text { on online social media. }\end{array}$ & .77 & .94 & \\
\hline
\end{tabular}




\begin{tabular}{|c|c|c|c|c|}
\hline Table 1 (Cont'd) & & & & \\
\hline Positive prejudice & 1. Israeli-Jewish suppliers are very honest in business dealings & .84 & .9 & .86 \\
\hline (adapted: Olson, 2009) & $\begin{array}{l}\text { 2. Israeli-Jewish suppliers provide high quality products and } \\
\text { services }\end{array}$ & .83 & .87 & \\
\hline & 3. I trust Israeli-Jewish suppliers & .81 & .85 & \\
\hline & 4. Isreal Jews suppliers are very professional. & .79 & .85 & \\
\hline Acculturation (adapted: & 1. I am pleased when I listen to Israeli music. & .8 & .96 & .79 \\
\hline Cuellar, Arnold, \& & 2. I feel satisfied when I use Hebrew & .86 & .98 & \\
\hline Maldonado, 1995) & 3. I like to define myself as an Israeli. & .85 & .98 & \\
\hline $\begin{array}{l}\text { Cross-shopping } \\
\text { intention (adapted: }\end{array}$ & $\begin{array}{l}\text { 1. Whenever possible, I will buy products and services from } \\
\text { outgroup suppliers. }\end{array}$ & .62 & .86 & .74 \\
\hline Hino, 2017) & 2. I am considering cross-buying to outgroup suppliers & .79 & .66 & \\
\hline & $\begin{array}{l}\text { 3. The likelihood of me cross-buying to outgroup suppliers is } \\
\text { High. }\end{array}$ & .6 & .94 & \\
\hline
\end{tabular}

(1) $\mathrm{CR}=$ Composite Reliability

(2) $\mathrm{AVE}=$ Average Variance Extracted

\section{Data Analysis and Hypotheses Test}

This study employs the Partial Least Squares (PLS) regression to examine the presented research structure. PLS-SEM allows researchers to analyse the measurement model simultaneously with the structural model, as well as to adopt research models with both moderating and mediating relationships. Specifically, PLS-SEM works efficiently when used to estimate path models comprising many constructs, several structural path relationships and/or many indicators per construct. Furthermore, PLS-SEM approach is less restrictive in sample size, sample data distribution, and measurement scales.

A structural model was built including all the antecedents and relevant relationships, enabling us to examine the hypothesised causal paths among the constructs by performing a simultaneous test. To assess the model fit with the data, it is recommended that the pvalues for the average path coefficient $(\mathrm{APC}=0.289, \mathrm{p}<0.01$ ) be lower than 0.05 . Convergent validity was evaluated to validate the measurement model through investigation composite reliability (CR) and average variance extracted (AVE). Table 2 illustrates that all CR and AVE values meet the recommended threshold values. On behalf of CR values are recommended to exceed 0.70 and AVE values should be greater than 0.50 (Hair et al., 2010).

Table 2: Composite reliability, VIF, AVE, and correlation of constructs' values

\begin{tabular}{|c|c|c|c|c|c|c|c|c|c|c|c|}
\hline Construct & Mean & SD & $\mathbf{C R}$ & VIF & AVE & 1 & 2 & 3 & 4 & 5 & 6 \\
\hline $\begin{array}{l}1 \text { Negative } \\
\text { prejudice }\end{array}$ & 2.1 & 1.45 & .82 & 1.48 & .61 & .78 & & & & & \\
\hline $\begin{array}{l}2 \text { Social } \\
\text { interaction }\end{array}$ & 3.7 & 1.04 & .83 & 1.74 & .51 & $-.25 * *$ & .72 & & & & \\
\hline 3 Online contact & 2.31 & 1.6 & .89 & 1.01 & .66 & $-.14 * *$ & $-.29^{* * *}$ & .82 & & & \\
\hline $\begin{array}{l}4 \text { Positive } \\
\text { prejudice }\end{array}$ & 3.03 & 1.13 & .9 & 1.29 & .7 & -.03 & $.33 * *$ & $.11^{* * *}$ & .84 & & \\
\hline 5 Acculturation & 2.94 & .48 & .89 & 1.39 & .73 & -.13 & .04 & .02 & .07 & .85 & \\
\hline 6 Cross-shopping & 3.31 & .99 & .72 & 1.34 & .55 & -.11 & $.38 * *$ & $.15 *$ & $.43^{* * *}$ & .01 & .7 \\
\hline
\end{tabular}

Note. $\mathrm{CR}=$ Composite Reliability; VIF = Full collinearity; AVE = Average Variance Extraction;

$* \mathrm{p}<0.05 ; * * \mathrm{p}<0.01$

As shown in Table 2, discriminant validity was evaluated by obtaining the AVE values for each variable. The square root of AVE for each variable is greater than the correlations between the variables and all other variables in the model, signifying that these variables have discriminant validity. VIFs were evaluated to check for the existence of collinearity. VIF values of less than 5 indicate no collinearity (Hair et al., 2010). Furthermore, all VIF values meet the recommended threshold values. Based on the current findings, this study demonstrates that the proposed model exhibits adequate reliability, construct validity, and collinearity. 


\section{Descriptive statistics}

The socio-demographic profile of the respondents is presented with respect to their gender, age group, educational background, and annual household income. Female respondents constitute $57.4 \%$ of the total sample. In terms of age, $25.7 \%$ of the respondents are between $18-35$ years old, $42.1 \%$ between $36-55$, and respondents aged 56 or older accounted for $32.2 \%$. More than $31 \%$ of the participants have a high school education, $9.7 \%$ have a college educational background, and an additional $29.6 \%$ have a university degree. Additionally, 52.8\% have a monthly household income of $\$ 3500$ or less, and 38.2 between $\$ 3501$ and $\$ 5500$. The rest of the respondents (9\%) earn over $\$ 5500$ a month.

\section{Results}

Figure 2 graphically displays the path coefficients and squared multiple correlations $\left(\mathrm{R}_{2}\right)$ for the endogenous constructs. The proposed conceptual model allowed a moderate amount of variance in the cross-shopping dependent variable $\left(\mathrm{R}_{2}=0.54\right)$. Almost all the hypothetical relationships were supported by the empirical model results, thus providing strong evidence for the hypotheses drawn from the theoretical framework. This means our conceptual model was able to capture both research goals: investigating the conflicting influence of positive and negative prejudice on cross-shopping intention in the context of ethnic minority-majority group relationship; and evaluating the moderating influence of intercultural factors on the relationship between negative prejudice and minority consumers intention to cross-shopping.

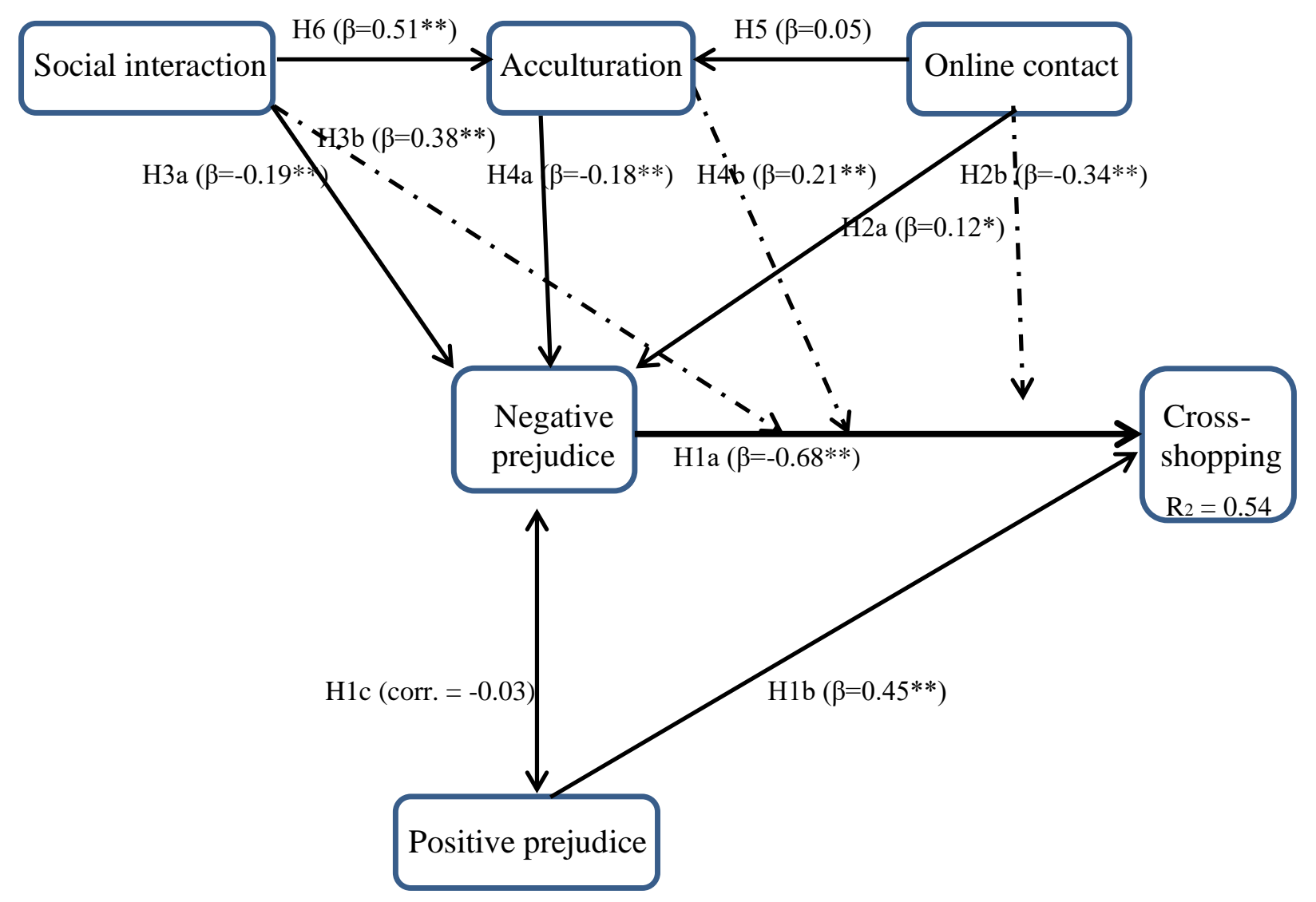

$* \mathrm{p}<0.05 ; * * \mathrm{p}<0.01$

Fig. 2: Estimated theoretical framework

H1a and H1b suggest that perceived prejudice have a conflicting influence on cross-shopping intention of minority members. The results reveal that the proposed relationship received statistical support. Perceived negative prejudice was found to decrease crossshopping intention (H1a: $\beta=-0.68, \mathrm{p}<0.01$ ), whereas positive prejudice drives consumers to cross-shopping to outgroup marketers (H1b: $\beta=0.45, p<0.01$ ). H1c proposed that negative and positive prejudices are negatively associated. However, the results did not support this prediction (H1c: corr. $=-0.03, \mathrm{p}>.05)$.

$\mathrm{H} 2 \mathrm{a}$ (online contact), $\mathrm{H} 3 \mathrm{a}$ (social interaction), and $\mathrm{H} 4 \mathrm{a}$ (acculturation) have a negative influence on perceived negative prejudice. The results demonstrate statistical support for the proposed relationships (H2a: $\beta=-0.12, p<0.05 ; \mathrm{H} 3 \mathrm{a}: \beta=-0.19, \mathrm{p}<0.01 ; \mathrm{H} 4 \mathrm{a}: \beta=-$ 
$0.18, \mathrm{p}<0.01)$. This means that these intercultural-related factors play an important role in reducing negative prejudices between minority and majority group members.

H5 asserts positive relationship between online contact and acculturation. The data did not support this hypothesis (H5: $\beta=0.05$, p $>0.05)$. Finally, H6 postulated positive relationship between social interaction and acculturation. The results show that the path from social interaction with outgroup members to acculturation of values of the dominant culture is significant and positive $(\beta=0.51$, $\mathrm{p}<0.01$ ), thus supporting H6.

As for the moderating effects of the intercultural factors on the relationship between negative prejudice and cross-shopping, the PLS results provide statistical support for the influence of online contact $(\mathrm{H} 2 \mathrm{~b}: \beta=0.34, \mathrm{p}<0.01)$, social interaction $(\mathrm{H} 3 \mathrm{~b}$ : $\beta=0.38, \mathrm{p}<0.01)$, and acculturation (H4b: $\beta=0.21, \mathrm{p}<0.01)$

\section{Implications}

The present study has several theoretical and managerial implications. From the theoretical perspective, this study contributes to the literature in several ways. Firstly, it contributes to the literature on ethnic consumer behavior by providing a new theoretical framework for understanding the effects of various inter-cultural factors on the cross-shopping intention of ethnic minority consumers. In particular, the study investigates the influence of social interactions, online contact, and acculturation on perceived negative prejudice and explains how reduced (negative) prejudice affects cross-shopping intention.

Secondly, the study serves as a pioneering effort to incorporate intercultural factors into empirical studies about changing consumer feelings and attitudes associated with minority-members' perceived (negative) prejudice, and the role these factors play in moderating the influence of prejudice on consumer buying decisions. Finally, the model introduced in the study investigates the role of positive prejudice on cross-shopping behavior and evaluates the correlation between it and negative prejudice. Furthermore, previous studies on intergroup relationships have mostly focused on key factors such as personal contact (online and offline) and social interactions, which in most cases tested the link between these factors and individual attitudes. Our study, however, is the first to explicitly incorporate a new factor (positive prejudice), together with a set of moderating variables (i.e. acculturation, social interaction, and online contact) into the research model. This implies that insights associated with this framework can be applied to other ethnic cultural groups in which social and cultural factors have a significant effect on behavior intention.

From a practical perspective, the study findings pose major strategic challenges for majority-group retail executives. Firstly, retail managers should enhance minority consumers' perceived positive prejudice by greater focus on benefits and advantages derived from crossing to attractive and trustworthy outgroup marketers. For example, outgroup managers can differentiate their offerings, thereby emphasizing product quality, by using cues valued and trusted by minority group consumers, such as crossing to a modern shopping environment which provides a comfortable and interesting shopping atmosphere, well-organized modern stores with professional customer service, and advanced retail technologies making it possible to generate cost economies and economies of scope. Moreover, though the study results highlight meaningful relationships between intercultural factors and minority member behavior, the knowledge that these are motives for cross-shopping intention would be very useful for managers in designing successful culture-based marketing strategies, especially when catering to different ethnic-cultural consumer groups worldwide. The study findings also suggest outgroup marketers can promote cross-shopping by encouraging online contacts and social interactions between minority and majority group members. Thus, the more frequent and intensive the intergroup members' personal interactions, the less negative prejudice they will perceive, and consequently, the greater the tendency to cross-buy.

Finally, the study of factors that affect perceived prejudice in the context of minority-majority group relationships is of major importance for public policy makers interested in accelerating social contacts between ethnic-cultural communities with the aim of reducing mutual negative prejudices and increasing assimilation of the minority population within the dominant one (Berry, 1997).

\section{Conclusions}

The overriding purpose of this study is to assess the influence of perceived prejudice on cross-shopping intention in the context of ethnic minority-majority group relationship. Specifically, this study seeks to provide a better understanding of the conflicting effects of both positive and negative prejudice on minority-consumers' intention to cross to majority-group marketers and suppliers for purchasing products and services.

Unlike most previous studies which have focused primarily on individuals' attitudes as a dependent variable, the current study examines the effects of a set of intercultural factors on behavioral intention, claiming these factors have both direct and moderating influence on cross-shopping behavior. Consequently, the current research is particularly important in that it is the first to focus on the role intercultural factors play in motivating ethnic-minority consumers to consider cross-shopping. Moreover, to the best of our knowledge, this is the first study that incorporates intercultural factors into a conceptual framework and investigates their influence on minority members perceived negative prejudice.

Many interesting findings are directly and tangentially related to the proposed hypotheses in the current study. On the whole, results point to conflicting effects of perceived prejudice (positive and negative prejudice) on cross-shopping intention. However, a striking finding to emerge from the study results reveals that, compared to the influence of negative prejudice on cross-shopping intention 
$(\beta=-0.17, p<0.01)$, the effect of positive prejudice is far higher $(\beta=0.46, p<0.01)$. Additionally, this finding constitutes initial evidence that the nature of perceived prejudice (negative vs. positive) affects individual behavior differently, not only in terms of impact direction, but also regarding intensity. This clearly offers an opportunity for outgroup marketers to position themselves as attractive and trustworthy retail destinations where minority consumers can purchase high quality products and high-level professional services. Combining this message with value would surely be a successful marketing strategy.

Consistent with what has now become a rather substantial literature (Erkan \& Evans, 2016; Hinz et al., 2011; Oyedele \& Hernandez, 2015; Ng, Kulik, \& Bordia, 2016; Pettigrew et al., 2011; Schumann, van der Linden, \& Klein, 2012), online contact and social interaction were found in the current study to negatively influence perceived prejudice. This means that frequent online contact and social interaction led to reduced prejudice among minority individuals as well as less negative feelings toward outgroup members.

Another important conclusion from the study results concerns perceived prejudice of majority members. Though online contact and social interaction were found to reduce negative prejudice among minority members, they would also suggest the same impact on perceived prejudice of majority-group members toward minority members. That is, the effects of intercultural communication involving minority and majority group members are bidirectional. This claim is centered on the contact theory (Allport, 1954), which states that individuals are likely to develop favorable perceptions of other outgroup members if the interactions between the groups' members are frequent and positive. This, too, is supported by past empirical research which found frequent personal contact and exposure to outgroup members led to improved intergroup relations, and a deeper understanding of and more positive attitude toward other outgroup members thus reducing (negative) prejudices (Brown \& Hewstone, 2005; Dovidio, Eller, \& Hewstone, 2011; Gaunt, 2011; Schumann, van der Linden, \& Klein, 2012; White and Abu-Rayya 2012; Wojcieszak \& Azrout, 2016).

The study results also shed light on the influence of acculturation on individual perceived negative prejudice. As hypothesized, acculturation was found to reduce perceived prejudice. This implies that as ethnic minorities become acculturated with the dominant population, and cultural elements are conveyed mutually and reduce perceived negative feelings and stereotypes. Likewise, social interaction was found to significantly influence acculturation, but in a way that enhanced minority members' tendency to adapt to the host mainstream culture. Consumers who maintain intensive close social interactions find it easier to adopt values and norms of the majority group (Wimmer \& Soehl, 2014), and are more likely to appreciate the benefits from engagement in buying activities with outgroup marketers.

Regarding the moderating variables (online contact, social interaction, and acculturation), the study results show all three constructs significantly moderate the relationship between negative prejudice and cross-shopping intention. The positive signs of the moderating variables coefficients clearly indicate that these variables appear to reduce negative influence of prejudice on consumer tendency to cross-shop to outgroup suppliers. Past research has shown that direct contact can lead to changes in individuals' opinions by improving the disposition toward outgroup members with whom they came into contact, and later, through improving individual position towards the outgroup itself, thus improving mutual relations (Allport, 1954; Brown \& Hewstone, 2005; Dovidio, Eller, \& Hewstone., 2011; Tausch \& Hewstone, 2010). Concerning social interaction, past research suggests intercultural social interactions enhance minority members' sense of belonging to the majority group members and their use of the dominant culture as a reference group (Glass \& Westmont, 2014). As such, individuals who interact extensively with majority group members are more likely to perceive engagement with majority group suppliers as acceptable behavior confirmed by their own social circle. Finally, as was previously noted, acculturation was found to moderate the negative relationship between prejudice and cross-shopping intention. This finding is consistent with previous studies that found acculturation reduces the gap between distinct cultures in terms of individual attitudes (Berry, 2001). Moreover, through acculturation, the majority's values may better resonate with minority consumers, who can consequently develop more positive attitudes toward transactions (products and services) offered by majority group providers.

\section{References}

Allport, G. W. (1954). The Nature of Prejudice. Reading: Addison-Wesley.

A' lvarez, C. M. O., Dickson, P. R., \& Hunter. G. K. (2014). The four faces of the Hispanic consumer: An acculturation-based segmentation. Journal of Business Research, 67(2), 108-115. https://doi.org/10.1016/j.jbusres.2012.11.010

Bar-Tal, D., \& Teichman Y. (2005). Stereotypes and prejudice in conflict: Representations of Arabs in Israeli Jewish society. New York: Cambridge University Press.

Berry, J. W. (1997). Immigration, acculturation, and adaptation. Applied Psychology, 46(1), 5-34. https://doi.org/10.1111/j.14640597.1997.tb01087.x

Berry, J. W. (2001). A psychology of immigration. Journal of Social Issues, 57(3), 615-631.https://doi.org/10.1111/0022-4537.00231

Berry, J. W. (2005). Acculturation: living successfully in two cultures. International Journal of Intercultural Relations, 29(6),697712. https://doi.org/10.1016/j.ijintrel.2005.07.013

Bojanic, D., \& Xu, Y. (2006). An investigation of acculturation and the dining-out behaviour of Chinese living in the United States. Hospitality Management, 25(2), 211-226. https://doi.org/10.1016/j.ijhm.2005.06.002

Brown, R., \& Hewstone, M. (2005). An integrative theory of intergroup contact. In M. P. Zanna (Ed.), Advances in experimental social psychology (37, pp. 255-343). San Diego, CA:Academic Press. 
Brylka, A., Jasinskaja-Lahti, I., \& Mähönen, T A. (2016). The majority influence on inter-minority attitudes: The secondary transfer effect of positive and negative contact. International Journal of Intercultural Relations, 50, $76-88$. https://doi.org/10.1016/j.ijintrel.2015.12.007

Byrd, W. C. (2014). Cross-racial interactions during college: A longitudinal study of four forms of interracial interaction among elite white college students. Societies, 4(2), 265-295. https://doi.org/10.3390/soc4020265

Chen, J., Aung, M., Zhou, L., \& Kanetkar, V. (2005). Chinese ethnic identification and conspicuous consumption: Are there moderators of mediators' effect of acculturation dimensions? Journal of International Consumer Marketing, 17(2-3), 117136. https://doi.org/10.1300/J046v17n02_07

Chiu, C., Hsu, M., \& Wang, E. (2006). Understanding knowledge sharing in virtual communities: An integration of social capital and social cognitive theories. Decision Support Systems, 42(3), 1872-1888. https://doi.org/10.1016/j.dss.2006.04.001

Cleveland, M., \& Chang, W. (2009). Migration and materialism: The roles of ethnic identity, religiosity, and generation. Journal of Business Research, 62(10), 963-971. https://doi.org/10.1016/j.jbusres.2008.05.022

Cleveland, M., Laroche, M., Pons, F., \& Kastoun, R. (2009). Acculturation and consumption: Textures of cultural adaptation. Journal of Intercultural Relations 33(3), 196-212. https://doi.org/10.1016/j.ijintrel.2008.12.008

Crisp, R., \& Turner, R. (2009). Can imagined interactions produce positive perceptions? Reducing prejudice through simulated social contact. American Psychologist, 64(4), 231-240. https://doi.org/10.1037/a0014718

Cuellar, I., Arnold, B., \& Maldonado, R. (1995). Acculturation rating scale for Mexican Americans-II: A revision of the original ARSMA scale. Hispanic journal of behavioural sciences, 17(3), 275-304. https://doi.org/10.1177/07399863950173001

Dato-on, M., Burns, D., Manolis, C., \& Hanvanich, S. (2006). Cultural assimilation and its effects on consumption behaviors: An examination of shopping behaviors and preferences of U.S. Hispanic immigrants. Journal of Shopping Center Research, 13(2), 107-138.

De Mooij, M., \& Hofstede, G. (2011). Cross-cultural consumer behavior: A review of research findings. Journal of International Consumer Marketing 23(3-4), 181-192.

Demangeot, C., Broderick, A.J., \& Craig, C.S. (2015). Multicultural marketplaces: New territory for international marketing and consumer research. International Marketing Review, 32(2), 118-140. https://doi.org/10.1108/IMR-01-2015-0017

Dienstbier, R. (1970). Positive and negative prejudice: Interactions of prejudice with race and social desirability. Journal of Personality, 38(2), 198-215. https://doi.org/10.1111/j.1467- 6494.1970.tb00004.x

Dovidio, J. F., Eller, A., \& Hewstone, M. (2011). Improving intergroup relations through direct, extended and other forms of indirect contact. Group Processes \& Intergroup Relations, 14(2), 147-160. https://doi.org/10.1177/1368430210390555

Dovidio, J. F., Gaertner, S., Kawakami, K., \& Hodson, G. (2002). Why can't we just get along? Interpersonal biases and interracial distrust. Cultural Diversity and Ethnic Minority Psychology, 8(2), 88-102. https://doi.org/10.1037/1099-9809.8.2.88

Eleta, I., \& Golbeck, J. (2014). Multilingual use of twitter: Social networks at the language frontier. Computers in Human Behavior, 41, 424-432. https://doi.org/10.1016/j.chb.2014.05.005

Erkan, I., \& Evans, C. (2016). The influence of eWOM in social media on consumers' purchase intentions: An extended approach to information adoption. Computer in Human Behavior, 61, 47-55. https://doi.org/10.1016/j.chb.2016.03.003

Fox, J., \& Warber, K. (2015). Queer identity management and political self- expression on social networking sites: A co-cultural approach to the spiral of silence. Journal of Communication, 65(1), 79-100. https://doi.org/10.1111/jcom.12137

Fujimoto, Y., \& Hartel, C. (2004). Culturally specific prejudices: Interpersonal prejudices of individualists and intergroup prejudices of collectivists. Cross Cultural Management; 113, 54-68. 10.1108/13527600410797846

Gaunt, R. (2011). Effects of intergroup conflict and social contact on prejudice: The mediating role of stereotypes and evaluations. Journal of Applied Social Psychology, 41(6), 1340-1355. https://doi.org/10.1111/j.1559-1816.2011.00762.x

Gautam, V., \& Sharma, V. (2017). The mediating role of customer relationship on the social media marketing and purchase intention relationship with special reference to luxury fashion brands. Journal of Promotion Management, 23(6), 872-888. https://doi.org/10.1080/10496491.2017.1323262

Glass, C. R., \& Westmont, C. (2014). Comparative effects of belongingness on the academic success and cross-cultural interactions of domestic and international students. International Journal of Intercultural Relations, 38, 106-119. https://doi.org/10.1016/j.ijintrel.2013.04.004

Greenland, K., \& Brown, R. (2005). Acculturation and contact in Japanese students studying in the United Kingdom. The Journal of Social Psychology, 145(4), 373-389. https://doi.org/10.3200/SOCP.145.4.373-390

Greenwald, A. G., Smith, C., Sriram, N., Bar-Anan, Y., \& Nosek, B. (2009). Implicit race attitude measures predicted vote in the 2008 U.S. Presidential election. Analysis of Social Issues and Public Policy, 9(1), 241-253. https://doi.org/10.1111/j.15302415.2009.01195.x

Hair, J. F., Black, W., Babin, B., \& Anderson, R. (2010). Multivariate Data Analysis. New Jersey: Pearson Prentice Hall Inc.

Hanna, R., Rohm, A., \& Crittenden, V. (2011). We're all connected: The power of the social media ecosystem. Business Horizons, 54(3), 265-273. https://doi.org/10.1016/j.bushor.2011.01.007

Hermann, T., Cohen, C., Omar, F., Heller, E., \& Lazar-Shoef, T. (2017). A Conditional Partnership: Jews and Arabs, Jerusalem: The Israel Democracy Institute.

Hino, H. (2014). Shopping at different food retail formats: understanding cross-shopping behaviour through retail format selective use patterns. European Journal of Marketing, 48(3/4), 674-698. https://doi.org/10.1108/EJM-12-2011-0764 
Hino, H. (2015). TV today, mobile TV tomorrow? Extrapolating lessons from Israeli consumers' adoption of innovative TV viewing technology. International Journal on Media Management, 17(2), 69-92. http://dx.doi.org/10.1080/14241277.2015.1030748

Hino, H. (2017). Does switching-intention result in a change in behaviour? Exploring the actual behavioural shopping patterns of switching-intended customers. British Food Journal, 119(12), 2903-2917. https://doi.org/10.1108/BFJ-12-2016-0622

Hinz, O., Skiera, B., Barrot, C., Becker, J. U. (2011). Seeding strategies for viral marketing: An empirical comparison. Journal of Marketing 75(6), 55-71. https://doi.org/10.1509/jm.10.0088

Hodge, S., Burden, J., Robinson, L., \& Bennett, R. (2008). Theorizing on the stereotyping of Black male student-athletes: Issues and implications. Journal for the Study of Sports \& Athletes in Education, 2(2), 203-226. https://doi.org/10.1179/ssa.2008.2.2.203

Husnu, S., Mertan, B., \& Cicek, O. (2018). Reducing Turkish Cypriot children's prejudice toward Greek Cypriots: Vicarious and extended intergroup contact through storytelling. Group Processes \& Intergroup Relations, 21(1), 178-192. https://doi.org/10.1177/1368430216656469

Josiassen, A. (2011). Consumer disidentification and its effects on domestic products purchases: An empirical investigation in the Netherlands. Journal of Marketing, 75(2), 124-140. https://doi.org/10.1509/jm.75.2.125

Kim, C., Laroche, M., \& Tomiuk, M. (2001). A measure of acculturation for Italian Canadians: Scale development and construct validation. International Journal of Intercultural Relations, 25(6), 607-637. https://doi.org/10.1016/S0147-1767(01)000281

Knowles, E., Lowery B., \& Schaumberg, R. (2010). Racial prejudice predicts opposition to Obama and his health care reform plan. Journal of Experimental Social Psychology, 46(2), 420-423. https://doi.org/10.1016/j.jesp.2009.10.011

Lavie, E. (2018). Integrating the Arab-Palestinian minority in Israeli society: Time for a strategic change. Institute for National Security Studies: Tel Aviv University.

Lee, E.J., Fairhurst, A., \& Dillard, S. (2002). Usefulness of ethnicity in international consumer marketing. Journal of International Consumer Marketing, 14(4), 25-48. https://doi.org/10.1300/J046v14n04_03

Leo, C., Bennett, R., \& Hartel, C.E. (2005). Cross-cultural differences in consumer decision-making styles. Cross Cultural Management, 12(3), 32-62. DOI: 10.1108/13527600510798060

Lysonski, S., \& Durvasula, S. (2013). Consumer decision making styles in retailing: Evolution of mindsets and psychological impacts. Journal of Consumer Marketing 30(1), 75-87. https://doi.org/10.1108/07363761311290858

Martinez, O., Wu, E., Shultz, A. Z., et al. (2014). Still a hard-to-reach population? using social media to recruit Latino gay couples for an HIV intervention adaptation study. Journal of Medical Internet Research, 16(4), e113. doi:10.2196/jmir.3311

McKelvy, L., \& Chatterjee, K. (2017). Muslim women's use of internet media in the process of acculturation in the United States. Qualitative Research Reports in Communication, 18(1), 18-26. https://doi.org/10.1080/17459435.2016.1247112

Mesch, G. S. (2012). Minority status and the use of computer-mediated communication: A test of the social diversification hypothesis. Communication Research, 39(3), 317-337. https://doi.org/10.1177/0093650211398865

Miller, D. A., Smith, E., \& Mackie, D. M. (2004). Effects of intergroup contact and political predispositions on prejudice: The role of intergroup emotions. Group Processes and Intergroup Relations, 7, 221-237. https://doi.org/10.1177/1368430204046109

Mor, Y., Ron, Y., \& Maoz, Y. (2016). “Likes” for peace: Can Facebook promote dialogue in the Israeli-Palestinian conflict? Media and Communication, 4(1), 15-26. http://dx.doi.org/10.17645/mac.v4i1.298

Mortazavi, M., Esfidani, R.M., \& Barzoki, S.A. (2014). Influencing VSN users purchasing intentions: The roles of flow, trust and eWOM. Journal of Research in Interactive Marketing, 8(2), 102-123. https://doi.org/10.1108/JRIM-08-2013-0057

Ng, Y. L., Kulik, C. \& Bordia, P. (2016). The moderating role of intergroup contact in race composition. Journal of Business and Psychology, 31(3), 415-431. https://doi.org/10.1007/s10869-015-9419-4

Oh, J. (2016), Immigration and social capital in a Korean-American women's online community: Supporting acculturation, cultural pluralism, and transnationalism. New Media \& Society, 18(10), 2224-2241. https://doi.org/10.1177/1461444816655627

Olson, M. (2009). Measures of prejudice. In T. D. Nelson (Ed.), Handbook of prejudice, stereotyping, and discrimination (p. $367-$ 386). Psychology Press.

Oyedele, A., \& Hernandez, M. (2015). Effect of intergroup-based emotions on attitude towards cross-ethnic products. Journal of Consumer Marketing, 34(1), 29-42. https://doi.org/10.1108/JCM-01-2015-1282

Paluck, E., \& Green, D. (2009). Prejudice reduction: What works? A review and assessment of research and practice. Annual Review of Psychology 60, 339-367. https://doi.org/10.1146/annurev.psych.60.110707.163607

Pettigrew, T. F., \& Tropp, L.R. (2006). A meta-analytic test of intergroup contact theory. Journal of Personality and Social Psychology, 90(5), 751-783. https://doi.org/10.1037/0022-3514.90.5.751

Pettigrew, T. F., Tropp, L., Wagner, U., \& Christ, O. (2011). Recent advances in intergroup contact theory. International Journal of Intercultural Relations, 35(3), 271-280. https://doi.org/10.1016/j.ijintrel.2011.03.001

Quester, P., Karunaratna, A., \& Chong, I. (2001). Australian Chinese consumers: Does acculturation affect consumer decision making? Journal of International Consumer Marketing, 13(3), 7-28. https://doi.org/10.1300/J046v13n03_02

Sandel, T. (2014). “Oh, I'm here!”: Social media's impact on the cross-cultural adaptation of students studying abroad. Journal of Intercultural Communication Research, 43(1), 1-29. https://doi.org/10.1080/17475759.2013.865662

Schumann, S., van der Linden, N., \& Klein, O. (2012). Bridging the gap on Facebook: Assessing intergroup contact and its effects for intergroup relations. Cyber Psychology Behavior, \& Social Networking, 15(8), 411-416. https://doi.org/10.1089/cyber.2011.0569 
Seger, C., Smith E., Percy E., \& Conrey F.R. (2014). Reach out and reduce prejudice: the impact of interpersonal touch on intergroup liking. Basic and Applied Social Psychology,36(1), 51-58. https://doi.org/10.1080/01973533.2013.856786

Segev, S. (2014). The effect of acculturation on ethnic consumers' decision-making styles: An empirical analysis of Hispanic consumers. Journal of International Consumer Marketing,26(3), 168-184. https://doi.org/10.1080/08961530.2014.889587

Shafaei, A., \& Abd Razak, N. (2018). What matters most: importance-performance matrix analysis of the factors influencing international postgraduate students' psychological and sociocultural adaptations. Quality \& Quantity 52(1), 37-56. https://doi.org/10.1007/s11135-016-0418-y

Smith, M., \& Li, Q. (2010). The boycott model of foreign product purchase: an empirical test in China. Asian Review of Accounting, 18(2), 106-130. https://doi.org/10.1108/13217341011059381

Tausch, N., \& Hewstone, N. (2010). Intergroup contact. In J. F. Dovidio, M. Hewstone, P. Glick, \& V. M. Esses (Eds.), Handbook of prejudice, stereotyping, and discrimination (pp. 544-560). London: Sage.

Taušová, J., Bender, M., Dimitrova, R., \& van de Vijver, F. (2019). The role of perceived cultural distance, personal growth initiative, language proficiencies, and tridimensional acculturation orientations for psychological adjustment among international students. International Journal of Intercultural Relations, 69, 11-23. https://doi.org/10.1016/j.ijintrel.2018.11.004

Tessler, M. (2009). A history of the Israeli-Palestinian conflict (2ed). Bloomington: Indiana University Press.

Üstüner, T., \& Holt, D. (2007). Dominated consumer acculturation: The social construction of poor migrant women's consumer identity projects in a Turkish squatter. Journal of Consumer Research, 34(1), 41-56. https://doi.org/10.1086/513045

Vijaygopal, R., \& Dibb, S. (2012). Exploring the role of acculturation in brand choice: A new perspective for targeting Indians living in the United Kingdom. Journal of Targeting, Measurement and Analysis for Marketing, 20, 47-56. https://doi.org/10.1057/jt.2012.4

White, F.A., \& Abu-Rayya, H.M. (2012). A dual identity-electronic contact (DIEC) experiment promoting short - and long-term intergroup harmony. Journal of Experimental Social Psychology, 48(3), 597-608. https://doi.org/10.1016/j.jesp.2012.01.007

Wimmer, A., \& Soehl, T. (2014). Blocked acculturation: Cultural heterodoxy among Europe's immigrants. American Journal of Sociology, 120(1), 146-186. https://www.jstor.org/stable/10.1086/677207

Wojcieszak, M., \& Azrout, R. (2016). I saw you in the news: Mediated and direct intergroup contact improve outgroup attitudes. Journal of Communication, 66(6), 1032-1060. https://doi.org/10.1111/jcom.12266

Zaglia, M. (2013). Brand communities embedded in social networks. Journal of Business Research, 66(2), $216-223$. https://doi.org/10.1016/j.jbusres.2012.07.015

Zick, A., Wagner, U., van Dick, R., \& Petzel, T. (2001). Acculturation and prejudice in Germany: Majority and minority perspectives. Journal of Social Issues, 57(3), 541-557. https://doi.org/10.1111/0022-4537.00228 